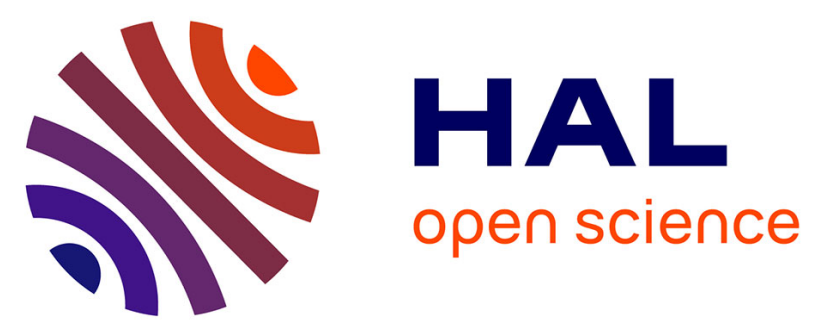

\title{
Study of the Elemental Partitioning for Different Transformation Conditions in the Ti-5553 Alloy
}

Charrier Guillaume, Moukrane Dehmas, Marion Descoins, Dominique

Mangelinck, Elisabeth Aeby-Gautier, Benoit Appolaire, Sandra Andrieu, Francis Soniak

\section{To cite this version:}

Charrier Guillaume, Moukrane Dehmas, Marion Descoins, Dominique Mangelinck, Elisabeth AebyGautier, et al.. Study of the Elemental Partitioning for Different Transformation Conditions in the Ti-5553 Alloy. Ti 2015 (the 13th World Conference on Titanium), Aug 2015, SAN DIEGO, United States. 10.1002/9781119296126.ch88 . hal-01521863

\section{HAL Id: hal-01521863 https://hal.science/hal-01521863}

Submitted on 12 May 2017

HAL is a multi-disciplinary open access archive for the deposit and dissemination of scientific research documents, whether they are published or not. The documents may come from teaching and research institutions in France or abroad, or from public or private research centers.
L'archive ouverte pluridisciplinaire HAL, est destinée au dépôt et à la diffusion de documents scientifiques de niveau recherche, publiés ou non, émanant des établissements d'enseignement et de recherche français ou étrangers, des laboratoires publics ou privés. 


\author{
STUDY OF THE ELEMENTAL PARTITIONING FOR DIFFERENT TRANSFORMATION \\ CONDITIONS IN THE Ti-5553 ALLOY \\ Guillaume Charrier ${ }^{1,2}$, Moukrane Dehmas ${ }^{1,3}$, Marion Descoins ${ }^{4}$, Dominique Mangelinck ${ }^{4}$, Elisabeth Aeby-Gautier ${ }^{1,3}$, Benoit Appolaire ${ }^{5}$, \\ Sandra Andrieu ${ }^{2}$, Francis Soniak ${ }^{6}$ \\ ${ }^{1}$ Institut Jean Lamour UMR 7198 CNRS-Université de Lorraine, Parc de Saurupt, CS 50840, F-54011 Nancy Cedex, France \\ ${ }^{2}$ Messier-Bugatty-Dowty, Etablissement de Bidos, BP 39, 64401 Oloron Ste Marie Cedex, France \\ ${ }^{3}$ Laboratory of Excellence for Design of Alloy Metals for Low-mass Structures ('DAMAS' Labex), Université de Lorraine, France \\ ${ }^{4}$ IM2NP, Faculté des Sciences et Techniques, avenue Escadrille Normandie Niemen, 13397 Marseille Cedex 20, France \\ ${ }^{5}$ ONERA-LEM, 29 avenue de la Division Leclerc, 92322 Chatillon France \\ ${ }^{6}$ Messier-Bugatty-Dowty, Inovel Parc Sud, 78140 Vélizy-Villacoublay, France
}

Keywords: Ti-5553 alloy, Chemical composition, Equilibrium state, TEM-EDX, Atom probe tomography

\begin{abstract}
The microstructure and the solute distribution inside the phases after isothermal holding in the temperature range between $420^{\circ} \mathrm{C}$ and $700^{\circ} \mathrm{C}$ in the Ti-5553 alloy were analyzed using TEM equipped with an EDX analyzer and atom probe tomography. When phase transformation occurred at high temperatures ( $\geq$ $600^{\circ} \mathrm{C}$ ), a significant partitioning of all solute elements was characterized. After a long holding time, the distribution was nearly homogeneous in each phase. For a transformation at lower temperature $\left(410^{\circ} \mathrm{C}\right)$, a low partitioning was observed at the beginning of the transformation, after $40 \mathrm{~min}$, and the precipitates composition notably evolved with increasing time toward an expected composition of equilibrium $\alpha$ phase.
\end{abstract}

\section{Introduction}

The use of $\beta$-metastable alloys in aeronautic industry is continuously increasing due to their excellent properties/weight ratio. Indeed, high yield strength and high ultimate strength can be obtained due to a large density of small $\alpha$ precipitates [1]. Ductility can also be optimized by creating a duplex microstructure [1] and controlling the amount and size of the primary and secondary $\alpha$ grains Extensive research is still dedicated to theses alloys in order to optimize their properties. Among the $\beta$ metastable alloys, the Ti-5553 alloy is a $\beta$-titanium alloy designed for the manufacturing of large section components such as landing gears. Its good quenchability allows a better control of the $\beta$ phase decomposition and results in a deep hardenability. To undertake the modeling of the formation and evolution of the microstructure, a good understanding of the phase transformation mechanisms involved is necessary. In addition to the structural changes, changes in chemical composition at the phase scale have to be characterized as well. During the transformation, $\alpha$ phase precipitates at multiple nucleation sites adopting different length scales and morphologies as a function of the transformation conditions.

In the case of the high transformation temperatures (about $100^{\circ} \mathrm{C}$ below the $\beta$ transus temperature), the growth kinetics is controlled by diffusion because the diffusion rate of the alloying elements is rapid enough [2,3]. For the lower temperatures (below $\mathrm{T}_{0}$ ), the nature of the transformation mechanism is still discussed since for this temperature range the lower diffusion rate and the higher driving force may lead to a partial displacive mechanism. Indeed, two trends can be found in the literature. Some authors [4,5] observed by TEM equipped with an EDX analyzer that the most part of partitioning of the alloying elements occurred only after the transformation completion, which would be partially displacive at a first stage, with limited partitioning. Other authors $[6,7]$ showed that the $\alpha$ phase produced during the transformation has a homogeneous chemical composition, close to the final equilibrium one while in the $\beta$ phase a concentration gradient is observed. Moreover, this was observed even for transformation temperatures about one hundred degrees below $\mathrm{T}_{0}$, where diffusionless mechanism is possible. In the case of $\beta$-metastable alloys and especially Ti-5553 alloy, the quantitative aspects of the partitioning at high and low temperatures are poorly documented. Nag et al. quantified the partitioning of solute elements in the Ti5553 alloy after isothermal holding from $\beta$ domain [8] and after annealing from full $\beta$ metastable state [9]. The authors showed a high molybdenum content in $\beta$ at the $\alpha / \beta$ interface after a short time at high temperature $\left(700^{\circ} \mathrm{C}\right)$ of which the amount may vary with the location of the $\alpha / \beta$ interface. They suggested that this accumulation at the interface can impact the kinetics and the morphology of the $\alpha$ phase. After annealing at low temperature $\left(400^{\circ} \mathrm{C}\right)$, they observed a more limited partitioning in the phases. They considered that if the higher driving force allows intragranular nucleation, diffusion necessary for the growth of the precipitates is less, limiting the partitioning between $\alpha$ and $\beta$. In addition to these post mortem investigations, time resolved XRD experiments have shown for Ti-5553 [10] and Ti 17 alloys [11] that the mean lattice parameter of the parent phase varies during the isothermal transformation, since its beginning for temperatures ranging between $800^{\circ} \mathrm{C}$ and $600^{\circ} \mathrm{C}$ and after longer times at lower temperatures $\left(400^{\circ} \mathrm{C}-450^{\circ} \mathrm{C}\right)$. Such behavior highlights the occurrence of solute diffusion during the transformation process.

These considerations prompted the present study that is focused on the characterization of the solute distribution within and near the $\alpha$ phase, which is isothermally formed after solution treatment in the $\beta$ domain in Ti-5553 alloy.

\section{Material and experimental procedures}

The nominal chemical composition of the Ti-5553 alloy is Ti-5Al$5 \mathrm{Mo}-5 \mathrm{~V}-3 \mathrm{Cr}-0.35 \mathrm{Fe}$ and $1500 \mathrm{ppm}$ of $\mathrm{O}$ and its $\beta$ transus is $848^{\circ} \mathrm{C} \pm 5^{\circ} \mathrm{C}$. Before heat treatments, its microstructure is duplex, 
with primary nodular $\alpha$ grains and acicular $\alpha$ grains, the latter lying within the parent $\beta$ matrix (Figure 1). Heat treatments were performed on cylindrical specimens $30 \mathrm{~mm}$ in length and $3 \mathrm{~mm}$ in diameter, using an in-house dilatometer that allows a simultaneous in-situ tracking of the phase transformation by measuring the electrical resistivity of the sample. All heat treatments started with a solution treatment in the $\beta$ field at $890^{\circ} \mathrm{C}$ for $30 \mathrm{~min}$, with a heating rate of $1^{\circ} \mathrm{C} . \mathrm{s}^{-1}$. Then, the specimens were quenched to the $\alpha+\beta$ field and isothermally held at $700^{\circ} \mathrm{C}$ for $48 \mathrm{~h}, 610^{\circ} \mathrm{C}$ for $48 \mathrm{~h}$ and $410^{\circ} \mathrm{C}$ for $40 \mathrm{~min}, 1 \mathrm{~h} 30$ and $48 \mathrm{~h}$, and finally quenched to room temperature in order to freeze the microstructure and the solute distribution.

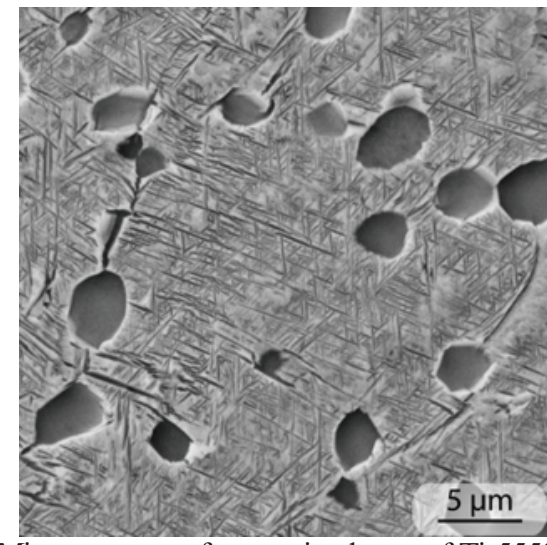

Figure 1. Microstructure of as-received state of Ti-5553 alloy.

Thin foils were prepared for TEM analysis using a dual-beam FIB, which contained both a focused gallium ion beam and a conventional field-emission scanning Electron FESEM column. FIB-TEM sample preparation offers two main advantages over conventional electropolishing technique. Firstly, the region to be thinned can be chosen with sub-micron precision. Secondly, coarsely heterogeneous microstructure consisting of chemically and structurally distinct regions can be uniformly thinned by FIB. A uniform thickness cannot be obtained by conventional electropolishing technique when the microstructure consists of both $\alpha$ and $\beta$ phases. As an example, Figure 2 shows a spatial thickness map obtained by EELS after conventional electropolishing. Consequently, the reliability of the chemical information needs to take into account the difference in thickness in each phase and the path of photons towards the detector.

Thin foils were investigated using JEOL AMR200F Cold FEG, operating at an acceleration voltage of $200 \mathrm{kV}$, and equipped with a GIF Quantum ER model 965 for EELS (Electron Energy Loss Spectroscopy) analysis and with a JEOL Dry SD detector for EDS analysis. For the quantitative chemical analysis care was taken of the determination of the local thickness to correct absorption and fluorescence. The foil thickness at each thin foil specimen was determined using electron energy -loss spectroscopy (EELS), with a total inelastic scattering mean free path of $93.3 \mathrm{~nm}$ for the selected conditions (collection semi-angle $(\beta)=20 \mathrm{mrad}$; incident energy $\left(\left(E_{o}\right)=200 \mathrm{kV}\right.$; mean energy loss $\left(E_{m}\right)$ which depends on the chemical composition of the specimen). The mean local thickness was estimated to range from 80 to $100 \mathrm{~nm}$, in satisfactory agreement with measurements estimated from the bend extinction contour of $g=[110]_{\beta}$ reflection. The quantitative chemical analysis was carried out in following the method developed by Cliff and Lorimer [12]. The $\mathrm{k}_{\mathrm{A} / \mathrm{B}}$ constants were determined from $\beta$-metastable state using electron probe microanalysis (EPMA).

For specimen transformed isothermally at $410^{\circ} \mathrm{C}$, the size of precipitates was too thin to be characterized by TEM from a chemical point of view. Consequently, 3D-APT investigations were conducted with an Imago LEAP 3000X-HR operating in pulsed laser mode, using a GaAs-Laser with a wavelength of 532 $\mathrm{nm}$. The obtained data were reconstructed and analyzed with the software package IVAS from IMAGO scientific instruments.
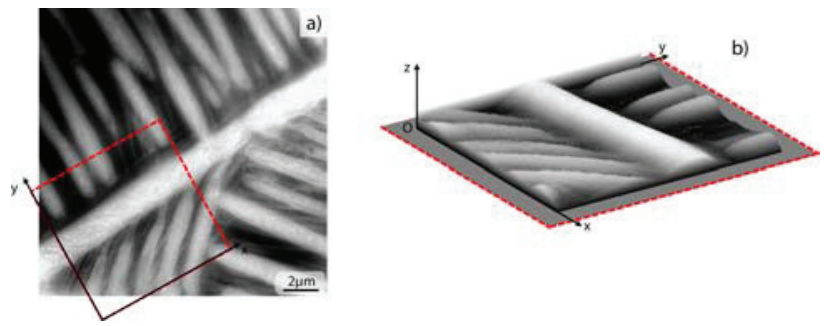

Figure2. TEM image (a) and corresponding spatial thickness map (b) obtained by EELS after conventional electropolishing.

\section{Results and discussion}

\section{$\underline{\text { SEM observation }}$}

Microstructure observations were performed at the end of each heat treatment. SEM micrographs are given in Figure 3. After being held for $48 \mathrm{~h}$ at $700^{\circ} \mathrm{C}$, the $\alpha$ phase appears with two main morphologies: continuous layers of $\alpha_{\mathrm{GB}}$ at grain boundaries and $\alpha_{\text {WGB }}$ colonies of Widmanstätten parallel sideplates, each colony growing from one $\alpha_{\mathrm{GB}}$ precursor [3, 13]. A hard impingement of these colonies is observed, so that the grain is entirely filled with a volume fraction of $\alpha$ phase close to $38 \%$. In some grains, the $\alpha$ phase is observed with a more intricate arrangement associated with intragranular precipitation of $\alpha$ plates nucleated on defects ( $\alpha_{\text {WI }}$ morphology). At lower temperature $\left(610^{\circ} \mathrm{C}\right.$ for $\left.48 \mathrm{~h}\right)$, the $\alpha$ phase, which is in majority of $\alpha_{\text {WI }}$ morphology type, has a very thin width and the volume fraction of $\alpha$ phase is about $53 \%$.

More specimens were observed for the temperature of $410^{\circ} \mathrm{C}$. Indeed, previous in situ high energy X-ray diffraction have shown that the decomposition of the $\beta$ phase started after $30 \mathrm{~min}$ by the formation of orthorhombic $\alpha$ " phase. As holding time increases, the precipitation amount increases and the diffraction peaks changed and tended toward those of the hexagonal $\alpha$ phase [10]. We thus consider that the crystallographic structure of this phase is a"/a. For specimen hold $40 \mathrm{~min}$ at $410^{\circ} \mathrm{C}$, the precipitation amount was low...A Widmanstätten star morphology is observed in the $\beta$ grains, which is similar to that observed by DehghanManshadi et al. [14]. These authors assumed that the morphology of the $\alpha / \alpha$ " phase can be explained by a mechanism of sympathetic nucleation. They rely on the works of Aaronson et al. [15] by proposing that the decomposition of the $\beta$ phase starts by the formation of the large plates of $\alpha$ phase followed by an edgeto-face sympathetic nucleation of small side-plates on the sides of the large plate. With the increase of the holding time, the microstructure tends to a homogeneous very finely distribution of $\alpha$ phase. 


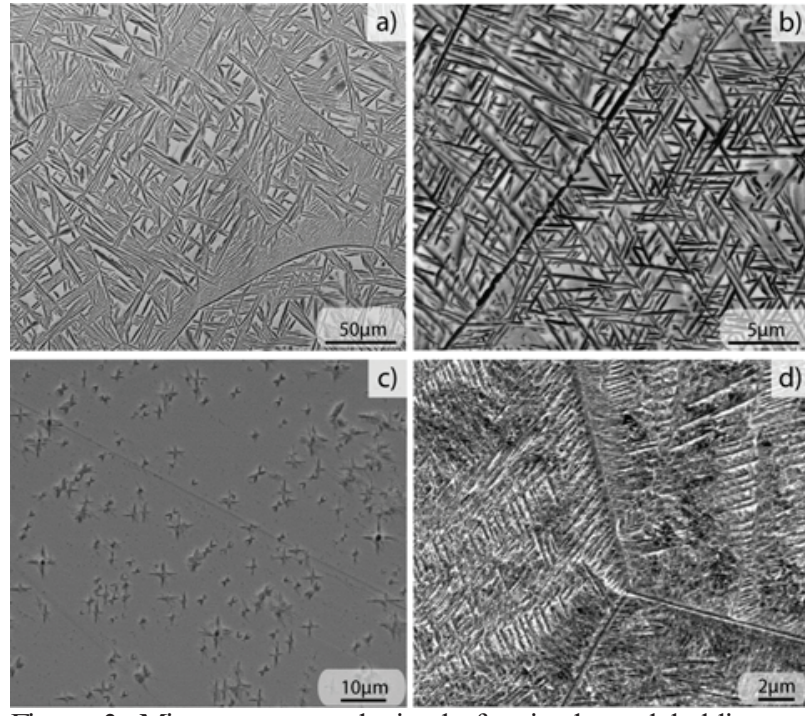

Figure 3. Microstructures obtained after isothermal holding and quenching: a) $700^{\circ} \mathrm{C}$ for $48 \mathrm{~h}$; b) $610^{\circ} \mathrm{C}$ for $48 \mathrm{~h}$; c) $410^{\circ} \mathrm{C}$ for 40 $\min$; d) $410^{\circ} \mathrm{C}$ for $48 \mathrm{~h}$.

\section{$\underline{\text { Chemical analysis }}$}

Figure 4 shows the microstructure and the corresponding element maps obtained by EDS after isothermal holding at $700^{\circ} \mathrm{C}$ for $48 \mathrm{~h}$. It should be mentioned that the $\mathrm{V}$ map could not be displayed because of the overlaps of the Ti- $\mathrm{K}_{\beta}$ and $\mathrm{V}-\mathrm{K}_{\alpha} \mathrm{X}$-ray lines. The analyzed area contains both the $\alpha_{\mathrm{GB}}$ grown along the boundary and $\alpha_{\text {WGB }}$ grown in the parent grain. The enriched $\mathrm{Mo}, \mathrm{Cr}$ and $\mathrm{Fe}$ maps are observed to be in coincidence with the $\beta$ phase and the enriched Al map with the $\alpha$ phase. Furthermore, the solute distribution in each phase seems homogeneous. Line scans were also performed across $\alpha_{\mathrm{GB}}$ and $\alpha_{\mathrm{WGB}}$. Figure 5 presents the solute distribution along path $\mathrm{AA}^{\prime}$ marked in Figure 4. Note that elements such as $\mathrm{O}$ and $\mathrm{N}$ were not examined due to the lack of accuracy of EDX analysis. These measurements reveal a partitioning of all elements, as expected, and a relatively close chemical composition for both $\alpha_{\mathrm{GB}}$ and $\alpha_{\mathrm{WGB}}$.. To ensure sustainability of the results, the EPMA analyzes were conducted on the same specimen. The EPMA technique is considered as the most reliable method for determining the chemical composition across a phase. The quantification results summarized in Table I are average values for both $\alpha_{\mathrm{GB}}$ and $\alpha_{\mathrm{WGB}}$ morphologies and for $\mathrm{Al}, \mathrm{Mo}, \mathrm{V}, \mathrm{Cr}$ and $\mathrm{Fe}$ elements. The comparison of the two methods shows slight differences but these differences can be considered as acceptable. The most probable reason for these discrepancies is the second order fluorescence excitation processes generated by the Bremsstrahlung radiation and the intensive Ti-K $\mathrm{K}_{\alpha} \mathrm{X}$-ray line.

Table I displays also the chemical composition estimated by thermodynamic calculations in $\alpha$ and $\beta$ at $700^{\circ} \mathrm{C}$. The calculations were made with the ThermoCalc software [16] using Saunders database for titanium systems [17]. It is seen that the chemical composition of both phases is quite close to the calculated one with ThermoCalc. This suggests that the chemical equilibrium is reached at least after the long dwell time at $700^{\circ} \mathrm{C}$. It should be noted that the $\alpha$ phase amount obtained experimentally by image analysis is also quite close.

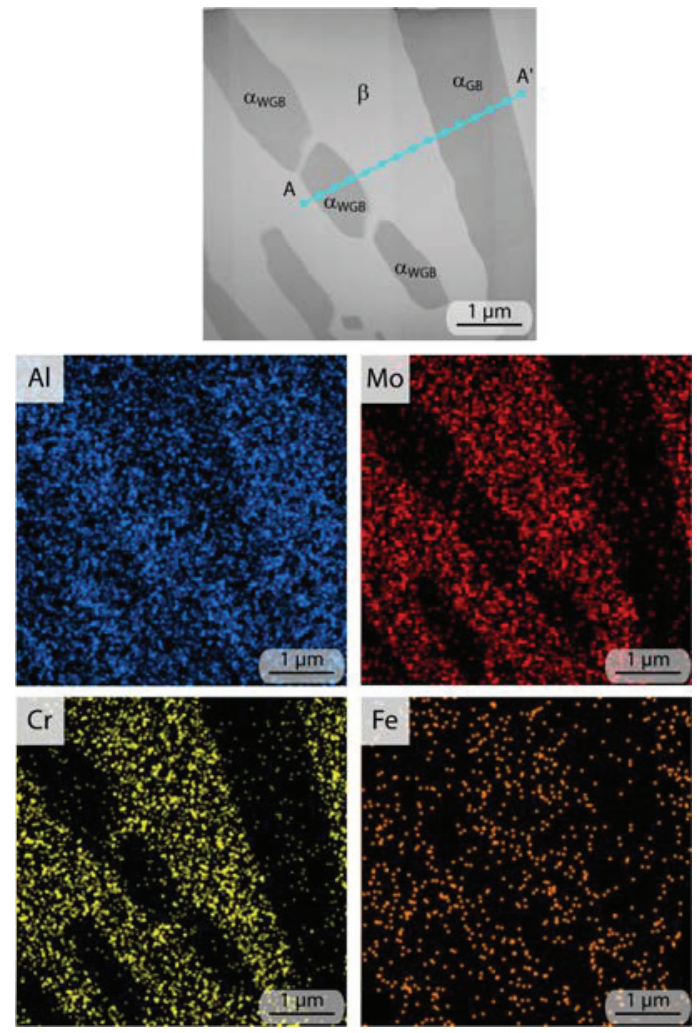

Figure 4. TEM observation and solute distribution in the $\alpha$ and $\beta$ phases after isothermal holding at $700^{\circ} \mathrm{C}$ for 48 hours.

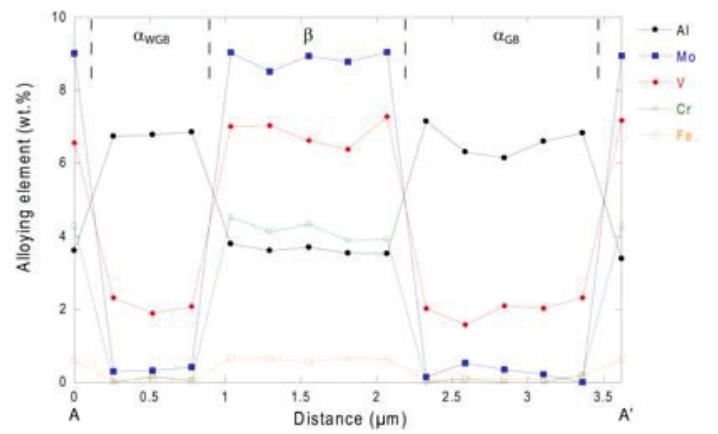

Figure 5. Solute distribution in the $\alpha_{\mathrm{GB}}, \alpha_{\mathrm{WGB}}$ and $\beta$ phases for the sample annealed at $700^{\circ} \mathrm{C}$ for $48 \mathrm{~h}$.

Table I. Comparison of the chemical composition in $\alpha$ and $\beta$ phases measured by TEM/EDX and EPMA after isothermal holding at $700^{\circ} \mathrm{C}$ for $48 \mathrm{~h}$ and thermodynamic equilibrium

\begin{tabular}{|c|c|c|c|c|c|c|}
\hline \multirow{2}{*}{$\begin{array}{c}\text { Element } \\
\text { (wt. } \% \text { ) }\end{array}$} & \multicolumn{3}{|c|}{$\alpha$} & \multicolumn{3}{|c|}{$\beta$} \\
\hline & EDX & EPMA & Calc. & EDX & EPMA & Calc. \\
\hline $\mathrm{Al}$ & 6.8 & 6.3 & 5.8 & 3.7 & 3.6 & 4.3 \\
\hline Mo & 0.3 & 0.3 & 0.4 & 9.0 & 7.7 & 8.5 \\
\hline V & 2.0 & 1.4 & 1.2 & 7.0 & 6.8 & 7.5 \\
\hline $\mathrm{Cr}$ & 0 & 0.3 & 0.3 & 4.3 & 4.2 & 4.4 \\
\hline $\mathrm{Fe}$ & 0 & 0 & 0 & 0.6 & 0.6 & 0.7 \\
\hline
\end{tabular}


A similar approach was applied to the sample maintained 48 hours at $610^{\circ} \mathrm{C}$. As shown in Figure 6, the microstructure consists of thin $\alpha_{W I}$ plates separated by $\beta$ phase. The solute distribution in both phases, illustrated by the X-ray maps in the Figure 6 , is homogenous and a solute partitioning is still observed. Table II displays the average chemical composition in $\alpha_{\mathrm{WI}}$ and $\beta$ phases measured by TEM/EDX after isothermal holding at $610^{\circ} \mathrm{C}$ for 48 $\mathrm{h}$ and estimated thermodynamic equilibrium composition using ThermoCalc. The average chemical compositions of the $\alpha_{W I}$ and $\beta$ phases are quite close to thermodynamic equilibrium values. Moreover, the comparison of the average chemical composition of $\alpha$ phase obtained experimentally after being held for $48 \mathrm{~h}$ at $700^{\circ} \mathrm{C}$ and $610^{\circ} \mathrm{C}$ reveals clearly that their respective chemical compositions are very close. This finding suggests that the local equilibrium at the interface does not change significantly in spite of a change in size of the precipitates (i.e. of any stored elastic energy).
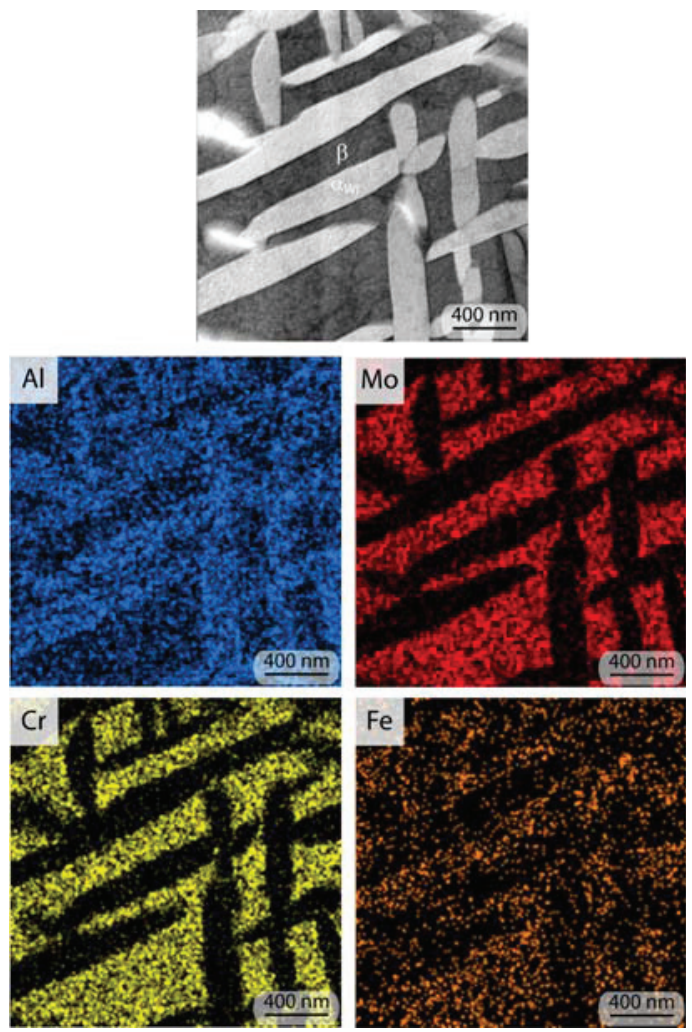

Figure 6. TEM observation and solute distribution in the $\alpha$ and $\beta$ phases after isothermal holding at $610^{\circ} \mathrm{C}$ for 48 hours.
Table II. Comparison of the average chemical composition in $\alpha_{\mathrm{WI}}$ and $\beta$ phases measured by TEM/EDX after isothermal holding at $610^{\circ} \mathrm{C}$ for $48 \mathrm{~h}$ and thermodynamic equilibrium composition predicted by ThermoCalc.

\begin{tabular}{|c|c|c|c|c|}
\hline \multirow{2}{*}{$\begin{array}{c}\text { Element } \\
\text { (wt.\%) }\end{array}$} & \multicolumn{2}{|c|}{$\alpha_{\mathrm{WI}}$} & \multicolumn{2}{c|}{$\beta$} \\
\cline { 2 - 5 } & Exp. & Calc. & Exp. & Calc. \\
\hline $\mathrm{Al}$ & 6.2 & 5.7 & 2.8 & 3.9 \\
$\mathrm{Mo}$ & 0.2 & 0.5 & 11.0 & 11.5 \\
$\mathrm{~V}$ & 1.9 & 1.2 & 8.4 & 9.9 \\
$\mathrm{Cr}$ & 0 & 0.3 & 5.4 & 5.9 \\
$\mathrm{Fe}$ & 0.1 & 0 & 0.8 & 1.0 \\
\hline
\end{tabular}

In the case of the samples held at $410^{\circ} \mathrm{C}$, the quantitative information was obtained by APT. The APT specimens were selected thanks to a dual-beam FIB. For specimen hold 40 min, the location with star morphology precipitates was selected, as transformed fraction is quite low. The interface between $\alpha / \alpha$ " and $\beta$ are delineated with Mo isoconcentration surfaces. Attention was paid to check that the average composition in the analyzed volume is the one of the Ti5553 alloy.

The average chemical composition in the precipitates and parent phase after various stages of isothermal holding at $410^{\circ} \mathrm{C}$ and thermodynamic equilibrium composition are given in Table III. At this isothermal holding temperature, it is important to remember that the incubation time is estimated to be about 30 min. Consequently, 40 min isothermal holding can be regarded as the first moment of the decomposition of the $\beta$ phase. The quantitative data show clearly that for the lowest holding time the average chemical composition of the precipitates evidences a partitioning of all elements, but much lower than that observed at higher temperatures and that extrapolated for equilibrium conditions using ThermoCalc. No thin spike of solute elements in front of the interface is observed. We can thus propose that precipitate inherits probably the chemical composition from its parent $\beta$ phase.

When the holding time increases, the concentration of the sole $\alpha$ stabilizing element ( $\mathrm{Al}$ ) is increased inside the $\alpha " / \alpha$ phase, while the concentrations of the $\beta$ stabilizing elements (Mo, V, $\mathrm{Cr}$ and $\mathrm{Fe}$ ) appear to be decreased inside the $\alpha " / \alpha$ phase. After isothermal holding for $48 \mathrm{~h}$, the aluminum content inside the $\alpha$ phase is close to thermodynamic equilibrium composition unlike the other elements, e.g. $\beta$-stabilizers. The concentrations of solute elements inside the $\beta$ phase vary significantly with the holding time but are still quite far from thermodynamic equilibrium composition for all solute elements. Thus, the higher the holding time, the lower $\alpha$ stabilizing content and the higher the $\beta$ stabilizing contents. It should be noted that Nag et al. [8,9] have studied the partitioning between the $\alpha$ and the $\beta$ phases after quenching from $\beta$ domain and subsequently annealing at $400^{\circ} \mathrm{C}$ for $2 \mathrm{~h}$. A slight partitioning between the two phases is also reported for $\mathrm{Al}, \mathrm{V}, \mathrm{Cr}$ and Mo with smooth composition changes that did not allow to define clearly an interface between precipitates and matrix. The maximal difference in $\mathrm{V}$ concentration profile is similar to the one obtained in this study after 90 min holding time. For the other elements some discrepancies are observed.

These experimental results indicate that at low temperature, the product phase forms with a composition far from that obtained after long holding times. After $40 \mathrm{~min}$ holding, a low partitioning of solute elements is characterized. Thus a diffusive process takes 
place very early. For longer holding times, the partitioning is larger and tends toward the one expected for the stable $\alpha$ phase. The reaction can be considered as incomplete, since the $\alpha$ phase has not reached its expected equilibrium composition. It can be mentioned that the amount of precipitated phase reaches a maximal value of $50 \mathrm{wt} \%$, value far from the one given by ThermoCalc [10].

The rejection of solute elements in the matrix may explain the change in mean lattice parameters of the precipitates as observed by HEXRD [10] as well as the late change in the mean lattice parameter of the $\beta$ phase as transformation progresses [10].

From these observations, one can expect that the nucleus has the same composition as that of the matrix or that some solute that diffuses rapidly (like oxygen) may control this first transformation step. As holding time increases, diffusion can operate, very slowly, and the $\beta$-stabilizer elements are rejected from precipitates while the $\alpha$-stabilizer content is enriched.

As transformation proceeds, the overall transformation kinetics occurs by an active nucleation process and growth. Indeed, the density and the size of the precipitates increase.

The performed analysis does not allow a statistical observation in order to precise if all new precipitates form with a composition near the one of the matrix and how the growth is controlled by the gradual redistribution of alloying elements between the matrix and the precipitate.

Table III. Evolution of the chemical composition in the $\alpha / \alpha "$ phase and the $\beta$ phase as a function of time at $410^{\circ} \mathrm{C}$ measured by APT and thermodynamic equilibrium composition predicted by

\begin{tabular}{|c|c|c|c|c|c|c|}
\multicolumn{2}{c}{} & \multicolumn{5}{c|}{ ThermoCalc. } \\
\cline { 3 - 7 } \multicolumn{2}{c|}{} & $\mathrm{Al}$ & $\mathrm{Mo}$ & $\mathrm{V}$ & $\mathrm{Cr}$ & $\mathrm{Fe}$ \\
\hline \multirow{4}{*}{$\alpha " / \alpha$} & $40 \mathrm{~min}$ & 5.3 & 2.5 & 2.9 & 1.2 & 0.2 \\
& $1 \mathrm{~h} 30$ & 5.4 & 1.7 & 2.4 & 0.8 & 0 \\
& $48 \mathrm{~h}$ & 5.8 & 1.5 & 2.2 & 0.4 & 0.1 \\
& Calc. & 5.7 & 0.4 & 0.8 & 0.1 & 0 \\
\hline \multirow{5}{*}{$\beta$} & $40 \mathrm{~min}$ & 5.0 & 4.9 & 5.9 & 3.4 & 0.4 \\
& $1 \mathrm{~h} 30$ & 4.9 & 5.8 & 7.6 & 4.6 & 0.6 \\
& $48 \mathrm{~h}$ & 3.8 & 9.3 & 11.4 & 7.1 & 1.1 \\
& Calc. & 2.5 & 24.8 & 15.4 & 6.2 & 2.1 \\
\hline
\end{tabular}

\section{Conclusion}

The solute distribution inside the phases during isothermal holdings in the temperature range between $700^{\circ} \mathrm{C}$ and $410^{\circ} \mathrm{C}$ has been investigated. These chemical analyses revealed a diffusive character of the phase transformation, with a partitioning of all alloying elements. At high temperatures $\left(610^{\circ} \mathrm{C}\right.$ and $\left.700^{\circ} \mathrm{C}\right)$, the diffusive character of the transformation was confirmed. At the end of the transformation, the solute elements are nearly homogeneously distributed. In addition, the chemical composition of the $\alpha$ phase is constant in this temperature range and close to the equilibrium composition predicted by ThermoCalc. At the lower temperature $\left(410^{\circ} \mathrm{C}\right)$, the $\alpha " / \alpha$ precipitates are initially formed with a low partitioning, and then $\alpha$ stabilizing element
(Al) gradually enriches the $\alpha " / \alpha$ phase during isothermal holding while $\beta$ stabilizing elements are rejected.

The quantitative analysis of the distribution of the solute elements in the Ti-5553 alloy presented here will provide the background for further modeling of transformation kinetics.

\section{Acknowledgments}

The authors are keen to thank Messier-Bugatty-Dowty and the CEA-METSA network for its financial support and Dr. Jaafar Ghanbaja, from IJL, for his help with TEM.

\section{References}

1. G. Lütjering and J.C. Williams, in: Titanium - 2nd edition, edited by Springer (2007).

2. F. J. Gil, M.P. Ginebra, J.M. Manero and J.A. Planell, "Formation of $\alpha$-widmanstätten structure: effects of grain size and cooling rate on the widmanstätten morphologies and on the mechanical properties in Ti6Al4V alloy," Journal of Alloys and Compounds, 329 (2001), 142-152.

3. M. Dehmas, J. Kovac, B. Appolaire, E. Aeby-Gautier, B. Denand and J. Teixeira. $\beta \rightarrow \beta+\alpha$ isothermal phase transformation in Ti17 titanium alloy: chemical composition and crystallographic aspect," Diffusion and Defect Data Pt.B: Solid State Phenomena, 172-174 (2011), 396-401.

4. Y. Ohmori et al., "Formation of widmanstätten $\alpha$ structure in a Ti-6Al-4V Alloy," Mat. Trans. JIM, 35(4) (1994), 238-246.

\section{H. Sharma, Master Thesis, TU Delft, 2008}

6. M. Enomoto and M Fujita, "Analysis of the composition of $\alpha$ plates isothermally formed in titanium binary alloys," Met. Trans. A, 21A (1990), 1547-1556.

7. M. Enomoto and T. Yoshida, "Solute Partitioning during the Proeutectoid $\alpha$ Transformation in Ti- $\mathrm{X}_{1}-\mathrm{X}_{2}$ Alloys," ISIJ International, 31(8) (1991), 767-774.

8. S. Nag et al., "Elemental partitioning between $\alpha$ and $\beta$ phases in the Ti-5Al-5Mo-5V-3Cr-0.5Fe (Ti-5553) alloy," Philosophical Magazine, 89(6), (2009), 535-552.

9. S. Nag et al., " $\omega$-assisted nucleation and growth of $\alpha$ precipitates in the Ti-5Al-5Mo-5V- $3 \mathrm{Cr}-0.5 \mathrm{Fe} \beta$ titanium alloy," Acta Materialia, 57(7), (2009), 2136-2147.

10. A. Settefrati, "Experimental study and phase field modelling of $\alpha$ formation in near $\beta$ titanium alloys," (Ph.D. thesis, Université de Lorraine, 2012).

11. E. Aeby-Gautier et al., "Microstructural formation in Ti alloys: in situ characterization of phase transformations kinetics," JOM, 59(1) (2007), 54-58.

12. G. Cliff, G.W. Lorimer, "The quantitative analysis of thin specimens," Journal of microscopy, 103(2), (1975), 203-207. 
13. M. Salib el al., "Influence of transformation temperature on microtexture formation associated with $\alpha$ precipitation at $\beta$ grain boundaries in a $\beta$ metastable titanium alloy," Acta Materialia, 61(10), (2013), 3758-3768.

14. A. Dehghan-Manshadi and R.J. Dippenaar, "Development of phase morphologies during low temperature isothermal heat treatment of a Ti-5Al-5Mo-5V-3Cr alloy," Mat. Sci. Eng. A, 52(8) (2011), 1833-1839.

15. H.I. Aaronson et al., "Sympathetic nucleation: an overview," Mat. Sci. Eng. B, 32(3) (1995), 107-123.

16. Foundation for Computational Thermodynamics, ThermoCalc, Version N, Stockholm, Sweden, (2014).

17. N. Saunders, Titanium Database, Thermotech Ltd., Surrey Technology Centre, The surrey Research park, Guilford, Surrey GU25TG, U.K., (1998). 